\title{
A LEITURA DE TEXTO DE DIVULGAÇÃ̃O CIENTÍFICA NO ENSINO DE CINÉTICA QUÍMICA
}

\section{THE READING OF SCIENTIFIC DISSEMINATION TEXTS IN THE TEACHING OF KINETIC CHEMISTRY}

\author{
Jonatan Josias Zismann e-mail (jonatanzismann@gmail.com) \\ Universidade Federal da Fronteira Sul (UFFS), Cerro Largo, RS. \\ Sabrina Thais Bach e-mail (sabrinabach10@yahoo.com.br) \\ Escola Eugênio Frantz, Cerro Largo, RS \\ Judite Scherer Wenzel e-mail (juditescherer@uffs.edu.br) \\ Universidade Federal da Fronteira Sul (UFFS), Cerro Largo, RS
}

\begin{abstract}
Resumo: A presente proposta didática contempla uma prática de leitura vivenciada numa aula de Química do Ensino Médio. Para tanto fez-se uso de texto de divulgação científica devido a sua forma de linguagem ser mais acessível aos estudantes. Apresentamos a prática da leitura em uma turma que contemplou o conteúdo de cinética química. Os alunos foram divididos em grupos para a realização da leitura, posteriormente realizou-se uma escrita por meio de respostas à perguntas e, um diálogo acerca do TDC. Os resultados apresentados indiciam que a leitura oportunizou uma apropriação da linguagem química e otimizou as relações do conteúdo químico e o cotidiano, o que qualifica os sentidos atribuídos ao aprender cinética química.
\end{abstract}

Palavras-chave: Ensino de Química; Linguagem Química; Leitura.

Abstract: This report contemplates a reading practice experienced in a high school chemistry class. For this purpose, it was made use of text of scientific dissemination due to its form of language being more accessible to students. We present the practice of reading in a class that contemed content of chemical kinetics. The students were divided into groups to perform the reading, then a writing was performed through answers to the questions, and a dialogue about the TDC. The results presented indicate that reading opportunized an appropriation of the chemical language and optimized the relationships of chemical content and daily life, which qualifies the meanings attributed to learning chemical kinetics.

Key words: Chemistry Teaching; Chemical Language; Reading

\section{INTRODUÇÃO}

A proposta didática versa sobre uma prática de leitura que foi realizada no âmbito do Ensino Médio numa aula de química e consiste numa das atividades desenvolvidas junto à iniciação de pesquisa PIBIC-EM financiada pelo CNPQ/20182019. Tal iniciação além de promover a pesquisa com alunos da Educação Básica tem 
possibilitado uma maior interação universidade escola, de modo especial, em nossa pesquisa estamos desenvolvendo um estudo acerca dos Textos de Divulgação Científica (TDC) e, experienciando modos de uso do mesmo em sala de aula.

Partimos da compreensão de que a prática da leitura é essencial nos processos de ensino, pois proporciona o desenvolvimento da imaginação, da criatividade, da comunicação e do posicionamento crítico frente ao texto. Afirmamos com Francisco Júnior (2010, p. 221), que o professor de Ciências é também um professor de leitura. Em outras palavras, ele também é responsável em empreender oportunidades para que os alunos exerçam a leitura em sala de aula. Isso porque todas as disciplinas escolares são suportadas na linguagem e, apresentam termos específicos que precisam ser significados junto aos estudantes.

Nessa direção, Francisco Júnior (2010) aponta que o texto deve propiciar ao aluno não só a leitura da palavra a partir de sua experiência histórico-social (leitura de mundo) como também a possibilidade de o estudante reescrever o seu mundo, transformando, ao mesmo tempo, sua leitura da palavra inicial. Ou seja, que a prática da leitura possibilite um posicionamento do estudante frente à um determinado assunto. Acreditamos que quando o estudante é instigado à interpretar, à se posicionar frente ao texto ele vai ampliando a sua capacidade crítica e, com isso, qualifica os modos de escrita, de argumentação e de compreensão.

De modo especial o nosso olhar está voltado para a prática da leitura junto ao ensino de Química. Justificamos a escolha por essa prática devido aos modos de como a leitura é vivenciada em aulas de química, a qual se reduz, na maioria das vezes, na leitura do Livro Didático e não potencializa um diálogo acerca de termos químicos e a sua relação com o cotidiano (FLOR, 2015). Visando qualificar o modo de leitura nas aulas de química fizemos uso de um TDC o qual apresenta uma linguagem mais simples, os termos mais técnicos, científicos/químicos dialogam com aspectos sociais e históricos o que torna a leitura mais acessível no contexto da sala de aula.

No TDC as explicações de cunho mais científico se aproximam de fatos do cotidiano por meio de exemplificações. Isso facilita a compreensão do leitor frente aos aspectos mais específicos da química, e com isso o professor assume a contextualização 
do conhecimento e supera a perspectiva reprodutivista da transmissão de conteúdos químicos (TARGINO DE MOURA, SOUZA e SÁ CARNEIRO, 2019).

De um modo geral, o TDC, busca trazer os conceitos científicos para quem não é iniciado na ciência (GIORDAN, CUNHA, 2015) e apresenta características particulares que Ferreira e Queiroz (2012), com base em Zamboni, apontam como sendo: a cientificidade, didaticidade e laicidade. Segundo as autoras (2012) os traços de cientificidade são provindos do discurso científico, relacionados tanto à práxis científica como a possíveis consequências negativas de produtos da ciência. A laicidade traz indícios do discurso cotidiano e contempla diferentes formas de contextualização. E a didaticidade está relacionada a aspectos do discurso didático como explicações, retomadas e orientações metodológicas.

Assim, é possível afirmar que o TDC se diferencia dos textos de química costumeiramente presentes nos livros didáticos, também, difere de um artigo científico, pois neste o autor não aparece e não há a preocupação em estabelecer um diálogo com o leitor que não seja iniciado na área. No TDC o autor se faz presente, pode, em alguns casos, ser o personagem do texto e busca estabelecer um diálogo com o leitor.

No livro "Tio Tungstênio" de autoria de Oliver Sacks, por exemplo, o autor conta sua infância e de como a química estava presente no seu dia a dia. Cada capítulo do livro retrata alguma lembrança do autor; os acontecimentos são descritos e envolvem os conceitos químicos de forma contextualizada e cheios de detalhes, num movimento que convida o leitor à leitura. Outro exemplo de livro de TDC é o de autoria de Robert L. Wolke, cujo título é "O que Einstein disse a seu cozinheiro" que contempla aspectos da química com uma linguagem compreensível num diálogo com o cotidiano. A cada capítulo é abordado um assunto diferente, o qual é introduzido por meio de perguntas e, as respostas são as explicações do autor sobre aquele determinado assunto, num diálogo que envolve o leitor.

Ressaltamos que o TDC não tem como foco o ensino, mas ele pode ser utilizado em aulas como instrumento para auxiliar no processo de aprender como apontam Giordan e Cunha (2015). De modo geral, o emprego de TDC em sala de aula propicia aos alunos um contato com informações atualizadas sobre ciência e tecnologia, com acontecimentos de seu cotidiano, trazendo ainda aspectos curiosos, interessantes e 
divertidos, proporcionando uma outra maneira de ver a Química. Ele também pode estimular o desenvolvimento de habilidades de leitura, de espirito crítico e reflexivo, sempre num movimento de leitura orientada. Segue a descrição da prática realizada e do texto que foi escolhido.

\section{CONTEXTO DA PRÁTICA E TDC ESCOLHIDO}

A prática de leitura foi vivenciada numa turma de $2^{\circ}$ ano do Ensino Médio numa escola pública da cidade de Cerro Largo/RS. Foram utilizadas duas aulas de química e a finalidade consistiu em mostrar aos alunos uma outra maneira de ver o conteúdo químico por meio da leitura. A escolha por essa turma foi devido à bolsista PIBIC/EM ser aluna do $2^{\circ}$ ano. Além da leitura do TDC foi realizado posteriormente, em conjunto com bolsistas PIBIDQuímica e PETCiências, algumas atividades práticas experimentais relacionadas à Cinética Química, mas essas não são objeto de discussão do presente relato.

O TDC que foi escolhido para a leitura foi pincelado do livro "Barbies, Bambolês e Bolas de bilhar" de autoria de Joe Schwarcz, o título é "Apreciando tomates". Esse texto, contempla o amadurecimento dos tomates retratando aspectos do conteúdo químico: Cinética Química, o qual, estava sendo trabalhado em sala de aula. No texto há também outros conteúdos, chamados de fronteira (FERREIRA, QUEIROZ, 2011) como, por exemplo, química biológica e química orgânica. Acreditamos que os diálogos com tais conteúdos possibilitam uma contextualização da temática cinética química junto ao ensino de química.

O nosso olhar para com o TDC decorre da análise proposta pelas autoras Ferreira e Queiroz (2011) que sugerem que os TDCs sejam analisados em três perspectivas: a) de Conteúdo: atenção para a predominância de conteúdos considerados de acordo com a estruturação formal do conhecimento químico, normalmente presente no ensino escolar; b) Fronteira: que contempla conteúdos não tradicionalmente incluídos no ensino formal da química, mas a ela relacionados como a física, por exemplo; c) Temas transversais: não pertencem a nenhuma disciplina específica, mas permeiam todas elas, inclusive a química, como se a todas fossem pertinentes. 
As autoras (2011) apontam que a identificação do conteúdo tem potencial para subsidiar algumas das ações preliminares do professor quanto ao uso do TDC em sala de aula, essas identificações podem ser amadurecidas e solidificadas por meio da análise subsequentes e, com isso o professor poderá planejar o momento da inserção de um determinado TDC em sala de aula.

No livro "Barbies, Bambolês e Bolas de bilhar" os capítulos se caracterizam como histórias dos mais variados assuntos, que versam sobre saúde, alimentação, apresentam dicas úteis para a cozinha e, em todos esses diálogos há de certa forma conteúdos relacionados com a química. Cada capítulo está subdividido em subcapítulos que apresentam uma temática em comum. Esse modo de escrita torna cada subcapítulo de pouca extensão, tal fato, facilita levar os textos para a sala de aula pois se caracterizam como textos curtos com início meio e fim.

Para a realização da prática de leitura a turma de 24 alunos foi subdividida em 6 grupos, cada grupo ficou, portanto, com quatro alunos, os textos foram fotocopiados e distribuídos para leitura. A fim de conduzir a leitura cada grupo recebeu as seguintes questões:

1- Destaque no texto o que mais lhe chamou atenção. E explique por quê.

2- Foi possível localizar/identificar algum conteúdo relacionando com cinética química?

3- O que você faz ou quais medidas você realiza para retardar o amadurecimento das frutas em sua casa?

4- O que você achou do texto?

Cada grupo foi convidado a realizar a leitura do texto e a responder ao questionário. Na sequência da aula realizamos a socialização das respostas e um diálogo geral sobre o texto, para em seguida, realizar os experimentos. Seguem algumas imagens da prática de leitura (FIGURA 1) e, em seguida apresentamos um diálogo a partir da análise dos excertos selecionados das respostas dos estudantes acerca do TDC.

FIGURA 1: Imagens da prática de leitura do TDC 

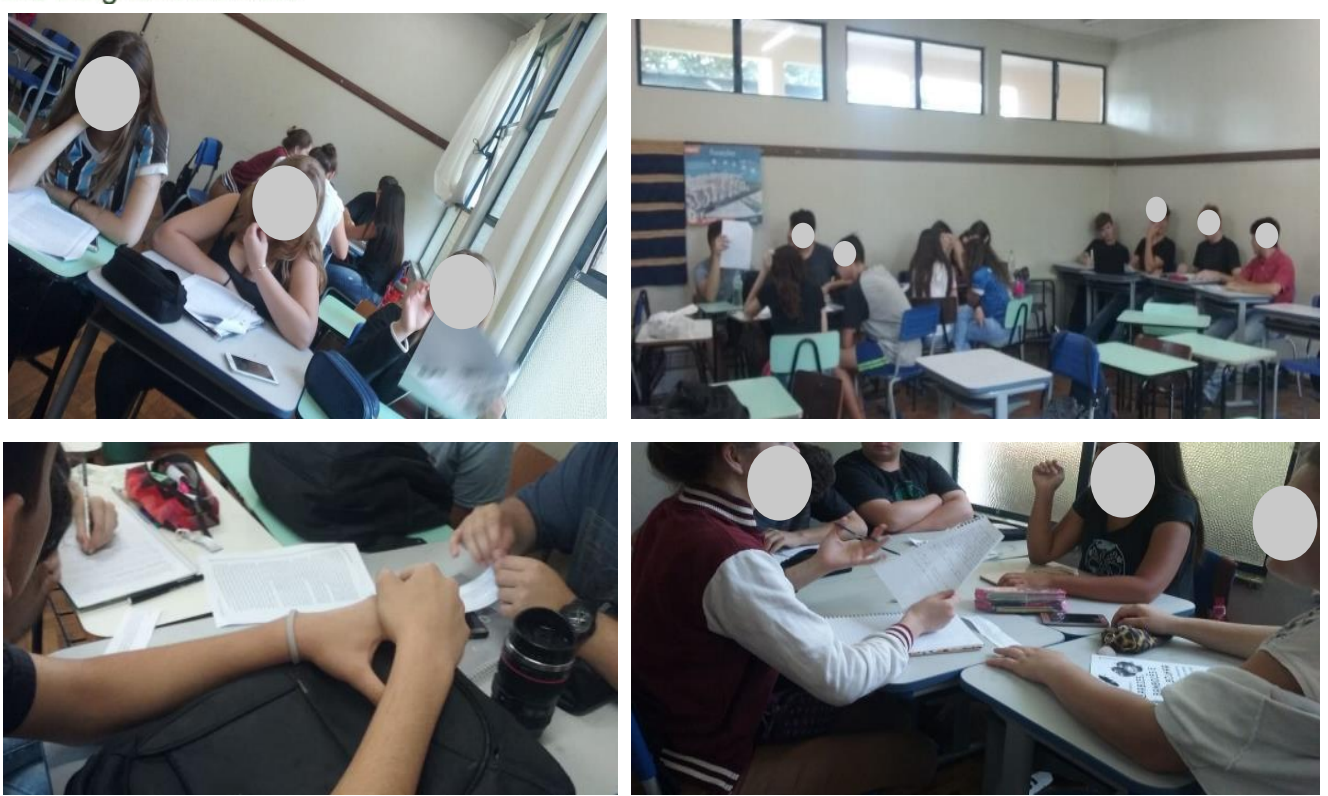

FONTE: Própria

\section{DIÁl OGO SOBRE A PRÁTICA}

A turma se mostrou interessada frente à leitura do TDC. Ao realizarmos a leitura das respostas dos estudantes frente ao questionário realizado agrupamos as mesmas em três grupos: a) parte da escrita que retratou de modo especial as curiosidades que o TDC trazia sobre a história do tomate e as próprias características do TDC; b) o uso de termos específicos químicos que caracterizam o conteúdo da cinética química; c) associações com aspectos do cotidiano. Cada um dos grupos de respostas está relacionado com as perguntas que foram encaminhadas incialmente.

Seguem as escritas de acordo com o agrupamento realizado:

A parte do texto em que eles descrevem que na Inglaterra e nos Estados Unidos o tomate era visto como um vilão, venenoso e responsável por uma variedade de doenças; já na Europa Continental ele era considerado afrodisíaco. E a parte que diz que o tomate, vagens, berinjelas e pepinos são considerados tecnicamente frutos. É um texto interessante, acessível $e$ compreensível. Traz curiosidades, como da cultura do tomate, coisas que não sabíamos. E mostra como a química pode estar 
no mínimos detalhes do nosso dia a dia. (Respostas a - essa resposta agrupa de modo resumido à todos os grupos).

Sim. Eles adicionavam etileno ao tomate verde, como sendo um catalizador, acelerando a maturação, mas só dava a cor, faltava o gosto. A Cinética Química se faz presente, na rapidez / velocidade do amadurecimento do tomate. (Respostas $b$, essa resposta foi pincelada dos grupos 01, 02 e 05).

Geralmente colocamos os alimentos na geladeira para conservar as frutas através do resfriamento delas, evitando o amadurecimento tão rápido, colocando jornal em torno delas, ou papel alumínio. (Respostas c - essa resposta indica as percepções de todos os grupos).

Ao olharmos para as respostas inseridas no grupo $a$ podemos visualizar algumas características que são próprias de um TDC, como ser "interessante, acessível e compreensível". O TDC utilizado em sala de aula apresenta uma linguagem simples e não traz muitos termos técnico-científicos, sendo repleto de procedimentos explicativos, os quais facilitam a compreensão do leitor frente aos aspectos mais específicos da química.

Mortimer (2014) também destaca que o TDC se caracteriza pelo seu tom de informação e alerta ao leitor. Percebe-se uma tentativa em promover uma tomada de conhecimento em relação à problemática de uma determinada situação ou fenômeno e isso ocorre sob a forma de apelo às consequências ambientais e à saúde humana. No texto que utilizamos em sala de aula, isso também ficou evidenciado:

[...] Essa posição extrema a um tomate geneticamente alterado não é cientificamente sustentável. Por algum tempo já alteramos a genética de nosso abastecimento de comida usando várias técnicas de cruzamentos, e não houve calamidades. Existe alguma preocupação legítima no entanto quando genes totalmente estranhos são inseridos em um alimento. Por 

exemplo, um gene das nozes foi recentemente inserido na soja para aumentar seu valor nutritivo como ração para animais. Algumas pessoas ficaram preocupadas, pois a soja alterada poderia desencadear alergias em pessoas com intolerância nozes. Testes cutâneos feitos com a soja transgênica confirmaram, de fato que essa era uma possibilidade [...] (SCHWARCZ, J. p. 85-86, 2009).

Ou seja, a linguagem que é utilizada nos TDCs busca envolver o leitor ao trazer exemplos do cotidiano, de fatos históricos e ainda, possibilita um posicionamento frente à situações polêmicas e controversas como o caso da modificação genética e saúde humana. Tais perspectivas vão ao encontro da necessária contextualização na qual,

os conteúdos curriculares de química precisam servir para a introdução do educando no mundo do conhecimento científico e da tecnologia, sendo estes utilizados para formar senso crítico na luta pelos seus direitos, no cumprimento de seus deveres, na defesa do próximo e do meio ambiente, etc (TARGINO DE MOURA, SOUZA, SÁ CARNEIRO, p. 11, 2019).

Esse movimento de contextualização, de compreender o cotidiano com aspectos da química implica na apropriação dos conhecimentos químicos e isso, requer a apropeição da linguagem química. De modo especial, na escrita que foi agrupada como respostas $b$, há indícios de uma apropriação da linguagem específica da química, pois os estudantes utilizaram termos específicos do conteúdo da Cinética Química e outros que apareceram no texto, como etileno, catalizador, rapidez/velocidade. A linguagem química se caracteriza como sendo muito específica e não é muito utilizada pelos alunos por se tratar de uma linguagem diferenciada, com especificidades e termos técnicos que requerem uma iniciação do estudante (WENZEL, MALDANER, 2016).

Com o aporte do referencial histórico cultural (VIGOTSKI, 2000) compreendemos que se apropriar dos termos da química é um caminho inicial para a aprendizagem, é um 
movimento essencial no processo de iniciar a significação conceitual. Ao fazer uso da palavra em diferentes contextos os sentidos atribuídos à ela podem ser orientados para um significado historicamente elaborado, daí a importância da leitura de TDC em sala de aula, pois o estudante passa a visualizar a palavra em diferentes contextos e é levado a fazer relações ou a identifica-las na leitura.

Um modo de relação consiste no diálogo entre aspectos da química e o cotidiano, os alunos nas respostas agrupadas como $c$, destacam aspectos do seu cotidiano, isso implica num movimento de pensamento que visa a relação com o que se está estudando em sala de aula com o seu dia a dia. A compreensão da linguagem cientifica permite ao aluno visualizar de outra forma os processos químicos que acontecem em seu cotidiano, compreendemos com Maldaner (2014, p. 20) que "a educação escolar é o tempo de questionamento do cotidiano vivido e tomada de consciência dos saberes e vivências que o configuram".

Assim o aluno ao compreender aspectos químicos em seu cotidiano passa a ter condições de exercer um posicionamento mais qualificado frente aos diferentes fenômenos e não os repete mais num mesmo nível de entendimento mas qualifica as suas ações. Com isso possibilitar por meio do TDC esse diálogo entre aspectos químicos e cotidianos pode ser um caminho para qualificar os sentidos que os estudantes atribuem para o aprender química num movimento qualificado de contextualização.

\section{CONCLUSÃO}

Os estudos acerca do uso e das características do TDC, bem como a prática de leitura vivenciada nos permitem afirmar que o uso da leitura do TDC em sala de aula possibilita aos estudantes uma maior significação dos conteúdos químicos. Ressaltamos a importância de uma prática de leitura orientada, conduzida por meio de estratégias de leitura, como o uso de perguntas, ou de escritas relacionadas à leitura.

Ressaltamos que os TDCs têm recebido destaque com seus benefícios sendo apontados na literatura especializada, os quais passam pelo simples estímulo ao hábito da leitura, podendo alcançar o desenvolvimento da capacidade crítica e uma 
compreensão mais adequada sobre a ciência (FERREIRA, QUEIROZ, 2015, p. 131), mas para isso, ressaltamos que a condução da leitura pelo professor é primordial.

Nessa direção, Ferreira e Queiroz (2015, p. 132) quando mencionam o uso de TDC em sala de aula apontam que "os estudos sobre intervenções em sala de aula empregando TDCs indicam a ocorrência de metodologias de ensino inovadoras e motivadoras, com a ressalva de que o seu uso requer uma preparação adequada dos professores, para que possam explorá-las apropriadamente”. Ou seja, é preciso planejar e elaborar muito bem as aulas de leitura, uma vez que, a leitura proposta não é apenas no sentido de o estudante reproduzir o que leu, mas que proporcione uma interação entre o leitor e o texto, que possibilite ao estudante se posicionar frente ao texto.

\section{REFERÊNCIAS}

CUNHA, M. B. da; GIORDAN, M. A divulgação Científica na Sala de Aula: Implicações de um Gênero. In: (Org.) Divulgação Científica na Sala de Aula. Ijuí, Ed. Unijuí, 2015, p. 67 - 86.

FERREIRA, L. N. de A.; QUEIROZ, S. L. Artigos da revista Ciência Hoje como recurso didático no ensino de química. Química Nova, v. 34, n. 2, p. 354-360, 2011.

FERREIRA, L. N. de A.; QUEIROZ, S. L. Textos de Divulgação Científica no Ensino de Ciências: uma revisão. Alexandria: Revista de Educação em Ciência e Tecnologia, v.5, n.1, p.3-31, 2012.

FERREIRA, L. N. de A.; QUEIROZ, S. L. Utilização de Textos de Divulgação Científica em Salas de Aula de Química. In: CUNHA, M. B. da; GIORDAN, M. (Org.) Divulgação Científica na Sala de Aula. Ijuí, Ed. Unijuí, 2015, p. 131 - 160.

FLOR, C. C. Na busca de ler para ser em aulas de química. Ijuí: ED. UNIJUİ, 2015, 208 p.

FRANCISCO JUNIOR, W. E.. Estratégias de Leitura e Educação Química: Que relações? In: Química Nova na Escola, vol. 32, n 4, nov 2010, p. 220-226.

MALDANER O. A. Formação de Professores para um Contexto de Referência Conhecido. In: NERY, B. K. ; (Org.). Formação de professores: compreensões em novos programas e ações. Ijuí, Ed. UNIJUÍ, 2014, p. 15 - 42.

MORTIMER, E. F. Aprender ciências: tensões e diálogos entre a linguagem comum e a linguagem científica. In: Cláudia Regina Flores; Suzani Cassiani. (Org.). 
Tendências contemporâneas nas pesquisas em Educação Matemática e Científica: sobre linguagens e práticas culturais. 1ed.Campinas: Mercado de Letras, 2014, v. , p. 185-202.

SACKS, O. Tio Tungstênio: Memorias de uma Infância Química. Trad. Laura Teixeira Motta, Brochura, $1^{a}$ ed., 2011.

SCHWARCZ, J. Barbies, bambolês e bolas de bilhar: 67 deliciosos comentários sobre a fascinante química do dia a dia. Trad. José Maurício Gradel, Rio de Janeiro: Zahar, 2009.

TARGINO DE MOURA, F.; SOUSA, R.; E SÁ CARNEIRO, C. O ensino de Química Contextualizado: as vozes discentes. Revista Insignare Scientia - RIS, v. 1, n. 3, 17 fev. 2019.

VIGOTSKI, L. S. A construção do pensamento e da linguagem. Trad. Paulo Bezerra. São Paulo: Martins Fontes, 2000.

WENZEL J. S.; MALDANER O. A. A prática da escrita e da reescrita orientada no processo de significação conceitual em aulas de química. In: Ensaio, Belo Horizonte, v.18, n. 2, p. 129 - 146, maio-agosto 2016.

WOLKE, R. L., O que Einstein disse a seu Cozinheiro: a Ciência na Cozinha. Rio de Janeiro: Zahar, 2003. 300 p. 